\title{
Designing a Digital Book History of Indonesia Fine Arts as a Learning Media in Class
}

\author{
R.A. Diah Resita I.Kuntjoro-Jakti, Arif Priyono Susilo Ahmad, Yusaira Farhia, Noor Udin \\ \{resitakj@binus.ac.id ${ }^{1}$, arifpsa@binus.edu² , yusaira@binus.ac.id ${ }^{3}$, nudin@binus.edu ${ }^{4}$ \} \\ New Media Program, Visual Communication Design Departement, School of Design, Bina Nusantara \\ University, Jakarta, Indonesia ${ }^{1,2,3}$, Creative Advertising Program, Visual Communication Design, \\ Deapartement, School of Design, Bina Nusantara University, Jakarta, Indonesia ${ }^{4}$
}

\begin{abstract}
Stereotyped as boring modules, some people considered theoretical-taught classes to be less interesting in comparison with the practice-as-research classes. One example of these theoretical classes is the History module. This research investigates how the educators in the History of Indonesia Fine Art module attempted to overcome these challenges by renewing their teaching techniques and using new media as tools to reach the objectives of the module. As a nature of history module, the History of Indonesia Fine Art module is packed with insights concerning the nation's ancient artefacts and their significances. It is designed to help the student to understand their ancestor's way of life through their material cultures. Ancient artefacts that generally are deemed as outdate objects actually possess incredible potential, for those who have learned its pastime significance and draw its correlation with today's society. The objective of the History of Indonesia Fine Art module is to encourage student to take history as their source of inspiration in creating their artworks. To help the learning process in the class, various methods and learning media were adapted each time. Now, with the increasing use of gadgets such as tablet or cellular phone, we can transform the History of Indonesia Fine Art into a digital book or e-book. This digital book will contain a lot more visual content than the previously printed books, which predominantly consist of texts. Student can use audio or video to learn and if there is an assignment, the student can do it online. With that background, the use of digital book of the History of Indonesia Fine Art can facilitate easier independent learning..
\end{abstract}

Keywords: history, teaching media, digital book

\section{Introduction}

During her years of teaching experience at the Visual Communication Design department of the Bina Nusantara University in Jakarta, Indonesia, the first semester of the education is focused in the basic knowledge. History of Indonesia Fine Art courses is one of the foundation classes that are compulsory for every student in the department. One of the obstacle on the first day meeting in the class is the class have low motivation and the student seemed not to be interested with the topics. So, since the beginning class, the students already have the stereotype of Indonesian Art History will be dull and always memoriez many things.

According to David P. Ausubel, an Education Psychologist, he relayed concerning the theory of meaningful learning. According to Ausubel, teacher's job is to make student 
understand and so students can be easily linking the experience of the knowledge relevant existing in the mind or inside their cognitive structure. So, Ausubel against memorize method in class because student will be hard to link their ability to make connection. (Thobroni, Mustofa, 2011: 101-102) Refer to this situation, memorizing years from the history will be hard for the student, it will be better if the student being teach to understand but not to memorize it.

Current teaching system has to many materials have to be deliver with a short time. A lecturer today should increase their knowledge faster in the era of rapid information like now, what happened one second a go is already a history. Other activities that can help students more understand about history is to visit the museum or gallery that show about the real artefact, but rarely have time to do it, so the student is not easy to understand and know about why they are learning because can not make the connection between the past and the present.

Realize this problems, teaching currently need more interactive media that can respond to this problems is by designing a digital book. The use of digital books can be operated through tablet or smart phones that is currently the students having high intensity of using it on daily life and easy to access as long there is a connection with the internet.

\section{Research Methods \& Literature Review}

\subsection{Research Method}

The Methodology was used in this research is descriptive research. According to Nazir (in idtesis.com), the descriptive method is a method in examining the status of the group of people, an object, a set of conditions, a system of thought or a class event in the present. The purpose of descriptive research is to get a systematic, factual and accurate description, visualization of the facts, traits and relationship between the phenomena investigated.

This study will explain how the conditions of the use of printed books and digital books in the lecture on Indonesia Art History. In this study there were several resource person as data retrieval object chosen by researchers in the research. The resource person consisted of Indonesia Art History lectures and class students who were asked about the design of this Indonesia History of Fine Art digital book.

\subsection{Literature Review}

Digital books are digital forms of books in various formats. Currently it has been widely used both for education and general purposes. E-book or digital book is believe to have begun in 1971 when Michael Hart started digitizing books in a project called Project Guttenberg. How ever the idea of a digital book began when Vanevar Bush wrote an article about Memex in "as we may think" (Press, 2000). Memex is a device in which an individual store all his books, records, and communications and in which is mechanized so that it may be consulted with exceeding speed and flexibility. It is an enlarged intimate supplements to his memory (Bush, 1945, p.7) (Priyanto, Sedyaningsih:2013).

Digital book appear in various forms. There are digital books that are marketed in forms database collection so we have to buy in a certain amount. Some are marketed in units of a certain price to download. There are digital books the buyer only pays (perpetual) and can be accessed for life, but also some are sold with subscription systems and digital books that are 
added or updated are not necessary must be paid again. Meanwhile digital books that can be read with a laptop or desk computer, but there are also digital books that are only read with certain media such as Kindle. Zipke (2012) says that most of the teachers were in awe of access to books provided by an e-reader. They commented in surprise of titles available to read. (p. 435).

Five benefits of digital books are: First, the small physical size; because the format is compact and can be stored as in disks, CDs, DVDs, etc. Secondly is easy to carry; printed book is heavily meanwhile digital book is very light. Third the digital book is not weathered like printed book can become obsolete. Fourth is easy to process; contents and digital books can be search easily and quickly and very beneficial for people who study literature. The fifth is can be used by anyone like people who cannot read, because the format can be processed by the computer, so the contents of digital books can be read by a computer using text through speech synthesizer.

The evolution of digital books or e-books that began in 1981 during that time, Random House published Electronic Thesaurus for the first time, which was the firs reference digital book. The era of digital books before year 20000 was not widely known especially by librarians or readers in Indonesia who were not familiar with digital information products in the form of e-books.

But now, with the advancement of technology, Zambarbueru D. and Carniglia E. (2012) stated that e-books and e-readers show advantages that printed books do not have because digital books can bring benefits to aspects of reading, particularly for text books and learning environment where the addition of multimedia can be a major advantage (p. 395).

For example, in a light weight digital book and a small format does not require large space to store it, e-books can be read anywhere and anytime, content can be updated easily, quickly and if there is an error can be corrected and added information can also be faster if compared to books print.

The development of the latest education system with the conditions told through the writing of Nuzulia Afrahunnisa in http://gondayumitro.staff.umm.ac.id/2011/04/realitas-sistempengajaran-di-indonesia/ dated 30 April 2011, indeed proves that the system Indonesia education needs reform. Reform efforts have not been supported by a precise and clear concept and there is no solid policy. Reform is essentially a comprehensive and fundamental change in all aspects of life. This comprehensive and fundamental change is also called a paradigm shift or systemic change.

This paradigm change (from civilization to student empowerment) affects all aspects of life and introduces new concepts. The four most important new concepts are learning, learning based on various sources (resource-based screening), school-based management, and alternative learning or education patterns (Thobroni and Mustofa:2011)

But the most interesting thing about all this is the use if information technology. All forms of technology are systems created by humans for specific purposes or make it easier for human to lighten their efforts, increase their results and save energy and resources. In the world of education, information technology creates network learning (online learning) which is a learning activity with non-traditional methods (must be face to face, directed or bound).

Learning media are media that carry messages or information that is instructional or contains teaching messages (Hamdani, 2011:243). Learning media is divided into several types: visual, audio-visual, computer-based and multi media based media, and what unites all through internet today is digital book. This is based on the Principle of Last Effort Theory, is a theory developed by Thomas Mann, a librarian from the US Library Congress. This theory explain s that humans tend to use tools that are simple, easily accessible, familiar with everyday and comfortable. Many researchers prefer to obtain information through easily accessible sources 
such as the internet rather than finding it in the library, even if in the library he will get better information.

However, learning media is everything that an be used for channel the message from the sender to recipient so that it stimulates the thoughts, feelings, attention and interests and wishes of students in such a way that learning process occurs in the framework of effective goals [1] Because the media used usually consists of several the media is called multimedia. [2] defines "multimedia" as a presentation of matter using words and pictures.

\section{Discussion}

The education system in Indonesia needs to revamp itself in order to fulfill the new education objectives, which are becoming a future channel of a new generation with creative attitude, logical rationale, and healthy physical state. When it comes to the Visual Communication Design, which has been mapped to be part of creative industry in Indonesia, the visual communication design education holds an important role to maintain their graduate, not only act as the craftmaker or idea conceptualizer, but also as creative and innovative inventor. [3] stated that the learning, thinking and creation process are in its principality equivalent to the process of imagination. In all those process, the medium of the communication are materialize in the for of "image".

To answer that challenge, the writer try to create an informative and interactive digital teaching materials with content that cultivate cognitive, affective and psychomotor domain for the art and design undergraduate student. The digital books that have been published by the publishers in America inspired this attempt. The transformation of the teaching materials from the conventional printed textbooks into the digital books that can be accessed by using tablet and/or smart phone was an interesting development, as shown in the videos (fig.1). It has shown in the video that the class became more active as the result from the interactive digital book.

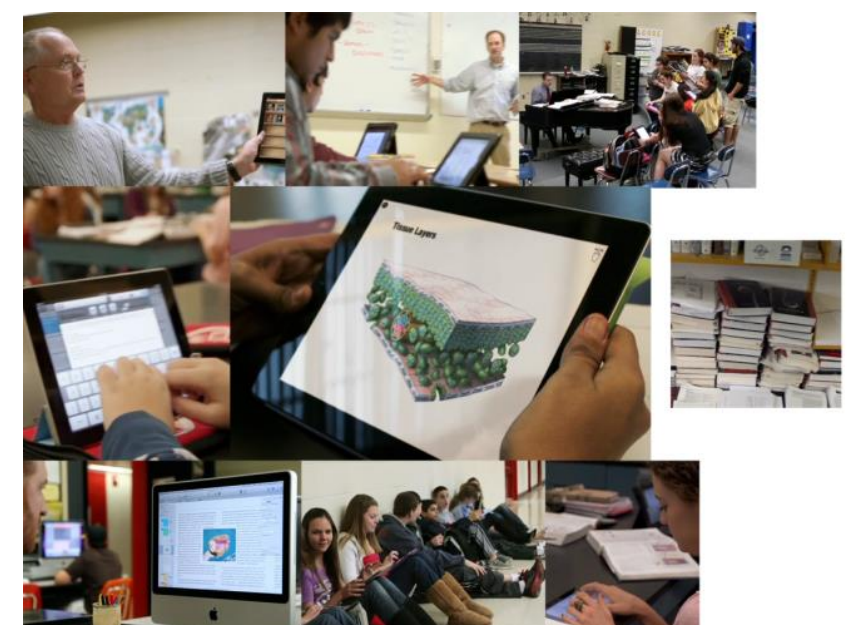

Fig. 1. The transformation of teaching medium, from printed book to digital book. (Bottom left shows a person in the middle of editing his digital book) (Source:

http://www.apple.com/education/profiles/burlington/\#video-burlington) 
It is not enough to rely on the ratio for the teaching process. The learning process needs to explore the student's creativity. One of the methods that can be utilized is the integrated learning method: habituating student to think in an integral manner, which brought together various knowledge disciplines that they have learned so far. Human thought is a collaborative process between ratio, creativity, and imagination. Thinking with ratio means we use a composed thinking framework. Creative thinking refers to the use of visual language and compiles them into something harmonious. Meanwhile, imaginative thinking is learning with visual imagining, or daydreaming.

A good learning is learning that that can develop the apprentice's creativity, with the use of critical thinking assignments, by using both verbal and visual language. One of the ways that can be performed is by creating a teaching medium that incorporated a playful element in it. Play $=$ creation $=$ experiment. Some benefits from learning-through-playing are: (a) It eliminates the element of seriousness that are seen as obstacle for some people, (b) It reduces the stress level in the learning environment, (c) It engages people, and (d) It improves the learning process. This is inline with the new design paradigm that was stated by Richard Grefe, the Executive Director of AIGA (America Institue of Graphic Arts) in the foreword page of the AIGA journal for Network Economy, in the year of 2000. On his statement, he mentioned that there has been emerged a new discipline in the design world in order to face the current world economy. This new discipline combines the societies' needs for a new communication formulation. This formula is Experience Design as a combination of Form, Content, and Context; divided by Time.

Experience design is a design comprehension that can surpass old habits. All these times, graphic design or visual communication design only focuses in the form, content, and context explorations. However, we need to add a new parameter, which is "time" as a crucial element that affecting the success rate of the communication delivery. This new development happened especially in the digital world/internet, where the information delivery happened vey fast, so that it changes the way the visual is being treated. No matter how instant, these visuals need to have strong meaning and background story.

Meanwhile, Wiyoso Yudoseputro likens Indonesian culture with the culture garden with various decorative richness of the archipelago. The development of these cultures is influenced by internal and external factors. The external factors come from the exposure with foreign cultures such as Indian, Islamic world, Western world, and East Asian; while the internal factors are came from the basic foundation of Indonesia culture ever since the prehistoric era.

Therefore, as one example of the use of the formula Experience Design = (form+content+context) : time, applied to the History of Indonesia Fine Art module is the Objective of the Artworks = (the design elements and principles+the meaning of the artefacts+the background story) : the way the artwork communicates under the constraint of certain period, which in current time deals with the internet era.

\section{Primary Target}

Profession: Student

Age: 18-20 years old

Gender: male and female

Demography: live in the cities and/or urban area

Psychography: the daily student lifestyle, heavily engaged with information from the digital world and/or internet, habitually play with online games, less interest to the printed publications, still engage with friends in real world, possibly involved with social/hobby 
communities. They are inseparable with their gadget such as laptop, smartphones and/or tablet which have became an integral part of their life.

\section{Secondary Target:}

Profession: teachers/educators

Age: $30-50$ years old

Gender: male and female

Demography: live in the cities, urban area and/or suburb

Psychography: mature lifestyle

Economical status: middle to upper class.

Those in between 30-40 years old started to know internet during their undergraduate and working period as professionals. They own several gadgets in their daily life, with at least smartphone and laptop. Those aged 50 years old and above know internet very well, but don't want to deal with complicated technology, therefore they generally still use gadget with intermediate technology, not too advanced. They need some time to get familiarize with tablet. However, once they master this gadget (tablet), it is very possible for them to use this gadget as a medium for teaching in the class.

To materialise the design of Indonesia Fine Art book, the writer uses several softwares that can help the design process. To edit the pictures the writer used Adobe Photoshop; to make info graphics and or simplified symbols/signs the writer used Adobe Illustrator. To edit the written materials the writer use Microsoft Word, and to combine them into a layout the writer iBooks Author, which is a special software for making digital book. The writer aspire to produce a digital book that is not only well-explored in terms of the content but also from its design as well. To avoid any redundancy in terms of the design with other digital books, the writer used as minimal as possible the available templates from the software. Even though iBooks Author software offers various templates for the book layout, the writer only use one of these templates for the chapter separators. 


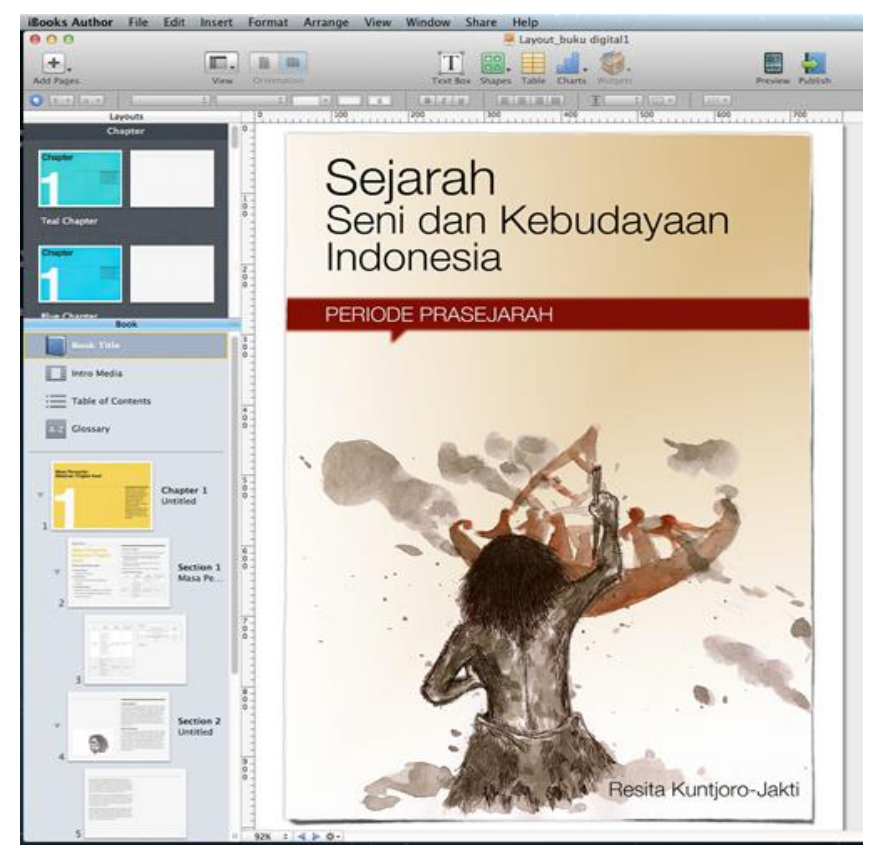

Fig 2. Designing e-book using softaware iBooks Author (Source: the writer's private documentation)

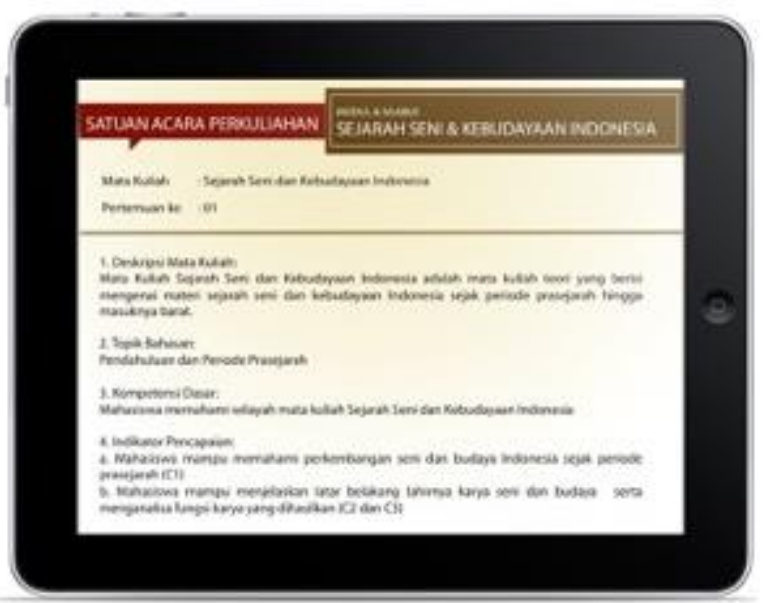

Fig 3. The design for the digital book as teaching material: front page (Source: the writer's private documentation) 


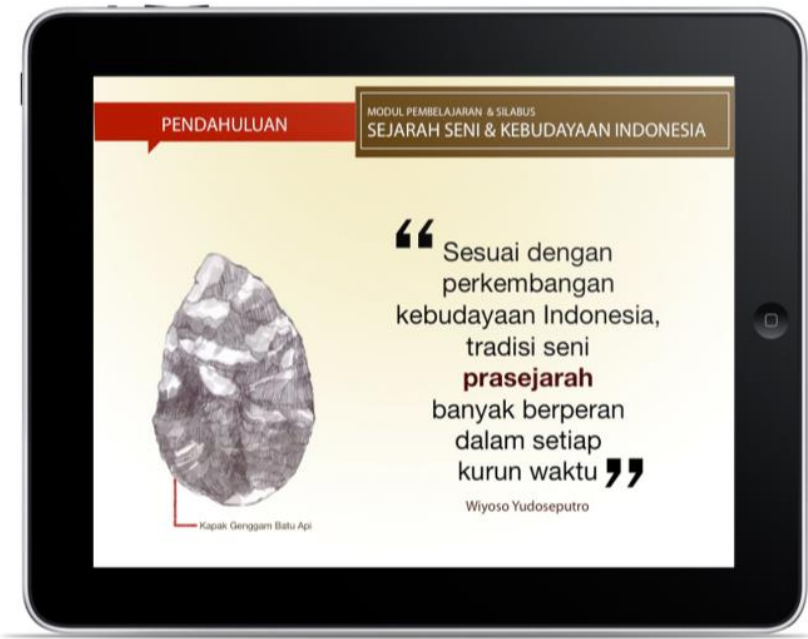

Fig 4. The design for the digital book as teaching material: not only touch on the cognitive subjects but also affection elements (Source: the writer's private documentation)

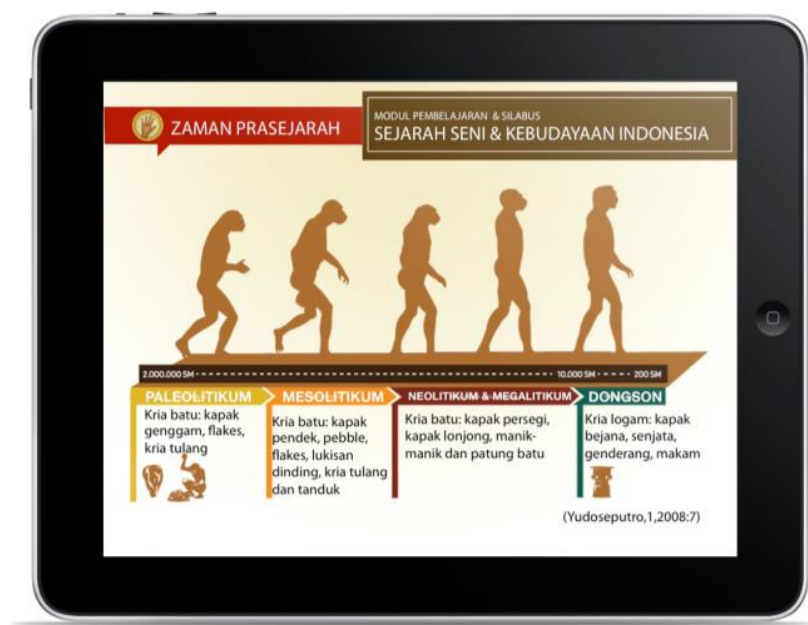

Fig 5. The design for the digital book as teaching material: the output can be varied, for example illustration, photo, and/or infographics. (Source: the writer's private documentation)

\section{Conclusion}

During the process of the making of the fine arts digital book, the writer found that basically almost all digital books only alter the medium of the book, without exploring the creative possibility of the medium. It resulted in another same old uninteresting books. Digital e-books which focusing in the historical topics is not an exception; which in principal only transform the medium from printed into the digital one. This is such a pity since digital book has potential to be creatively explored in a way that the conventional printed book unable to 
(or able but has a very expensive production cost). When the digital book explored, the writer has no doubt that it can be an interactive book that engage with its reader.

In this occasion, the writer wants to give advice to the prospective writers, to encourage them to start learning the potentiality of the digital book. Beside its design that visually pleasing the eyes and more suitable to the young generation, the software for the digital book also provide various facilities to create an interactive and engaging book. In reality, the writer predicts that the digital book will be the main source of knowledge for the young generation. Therefore, the time has arrived for the writers to change their writing paradigm to this new medium. However, they should also maintain their creative approach and not too heavily relied to the available templates from the digital book-making software.

\section{References}

[1] [9] Sukiman, Pengembangan Media Pembelajaran. Yogyakarta: PT. Pustaka Insan Madani, 2012.

[2] R. E. [4] Mayer, Multimedia Learning, Edisi Baha. Yogyakarta: pustaka pelajar, 2009.

[3] P. [11] Tabrani, Proses Kreasi, Apresiasi, Belajar. Bandung: Penerbit ITB, 2000. 